\title{
Transversalidades corporais: o corpo entre clínica, educação e saúde
}

\author{
Fernando Yonezawa, Fabio Hebert da Silva ${ }^{\star}$ \\ Universidade Federal do Espírito Santo, Vitória, ES, Brasil
}

\begin{abstract}
Resumo
Este texto de cunho conceitual objetiva apresentar um estudo acerca das concepções de corpo presentes nas obras de Keleman e de Deleuze/Guattari, realizando um diálogo crítico que seja capaz de estabelecer uma linha de transversalidade entre os campos da clínica, da educação e da saúde. Apresentando conceituações destes autores e trazendo ainda alguns elementos nietzschianos e spinozanos para a discussão, pretendemos mostrar que um corporalismo capaz de transversalizar clínica, saúde e educação irá implicar-se eticamente em produzir alegria, porém, tomando-a como afeto que norteia o exercício educacional e promotor de saúde de ampliar a capacidade de agir e ser afetado.
\end{abstract}

Palavras-chave: corpo; clínica; educação; saúde; transversalidade.

\section{Body Transversalities: body between clinic, education and health}

\begin{abstract}
This conceptual text aims to present a study about the conceptions of body present in the works of Keleman and Deleuze / Guattari, accomplishing a critical dialogue that could be able to establish a line of transversality between the fields of clinic, education and health. Presenting the conceptualizations of these authors and bringing some elements from Nietzsche and Spinoza to the discussion, we intend to show that a corporalism capable of transversalizing clinical, health and education will be involved ethically in producing joy, but taking it as affection that guides the educational and health promoter exercise of expanding the ability to act and being afected.
\end{abstract}

Keywords: body; clinic; education; heath; transversality.

\section{O corpo, em que consiste?}

Neste estudo conceitual, gostaríamos de encontrar uma linha de transversalidade que passe pelos campos da clínica, saúde e educação, a partir do corporalismo que encontramos em Deleuze/Guattari e Keleman. Para isso, também iremos trazer alguns elementos do pensamento spinozano e nietzschiano. Ressaltamos que nossa intenção aqui não é fazer uma crítica a Keleman ou a Deleuze/Guattari, mas destacar possíveis pontos de diálogo, apontando também diferenças nas concepções de corpo. É necessário, então, que apresentemos a conceituação de corpo que deverá nos nortear numa incursão corporalista.

Baseando-nos primeiramente em Deleuze e Nietzsche, sabemos que um corpo é um composto heteróclito de forças. "Qualquer relação de forças constitui um corpo: químico, biológico, social, político" (DELEUZE, 2001, p. 62). Quer dizer, o corpo, ao ser constituído por diferenças, forma "quantidades de força 'em relação de tensão' umas com as outras", forma uma multiplicidade. Por isso, para formar um corpo, só havendo uma combinação complexa; sendo a complexidade não só a qualidade daquilo que é feito de muitas partes diferentes, mas também por ser feita de relações tensas, em estado de desequilíbrio. "O princípio da tensão dá liga às singularidades fenomenais da vida, afirma a processualidade energética do universo [...]" (BAIOCCHI; PANNEK, 2007, p. 53). É a diferença a função que liga as forças existentes no corpo. "O corpo é um fenômeno múltiplo, sendo composto por uma pluralidade de forças irredutíveis; a sua unidade é a de um fenômeno múltiplo [...]" (DELEUZE, 2001, p. 63). O corpo é imediatamente vários,

\footnotetext{
${ }^{4}$ Endereço para correspondência: Universidade Federal do Espírito Santo, Departamento de Psicologia. Goiabeiras - Vitória, ES - Brasil. CEP: 29075910. E-mail: fefoyo@yahoo.com.br, fabiohebert@gmail.com
}

comunidade de desiguais. Daí a importância da palavra 'irredutível' presente no trecho citado acima: nenhuma força esgota o corpo ou o essencializa na forma de uma substância. "Quando olhamos os corpos, percebemos que não estamos somente diante de uma multidão de corpos, mas compreendemos que cada corpo é uma multidão" (NEGRI, 2003, p. 170).

Mas, se é assim, como é que estas inúmeras forças se mantém juntas, ou seja, como o corpo consegue formar esta unidade que conhecemos? Novamente é preciso destacar a importância da palavra irredutível: o corpo só pode formar uma unidade coesa mantendo a irredutibilidade da multiplicidade que o constitui. O problema passa a ser: "como o diferente, o heterogêneo se mantém junto?" (DELEUZE; GUATTARI, 1997, p. 138). Nesta passagem do volume 4 de Mil platôs, Guattari e Deleuze buscam uma forma de compreender o que faz manterem-se juntos inúmeros componentes distintos, sem que, contudo, se explique essa "soldagem" através de um modelo arborescente, o qual remeta a coesão das forças a um eixo de equivalência para todos os elementos. Por isso é que estes autores lançam o conceito de consistência. As forças se soldam na medida em que acontecem entre elas, "densificações, intensificações, reforços, injeções, recheaduras, como outros tantos atos intercalares ('não há crescimento senão por intercalação'); [...]. [E vejamos, ainda que para haver preenchimento] "é preciso que haja acomodação de intervalos, repartição de desigualdades" (DELEUZE; GUATTARI, 1997, p. 140). Então, o encontro de forças consolida um corpo, cria uma consistência. Enfim, se um corpo é relação tensa de forças heterogêneas, a qualidade de um corpo é dada pela consistência das relações de força que o criam, isto é, pela quantidade de diferença que ele suporta, sustenta, comporta. Tanto mais consistente 
um corpo, quanto possua mais quantidade de diferença. "O que torna o material cada vez mais rico é aquilo que faz com que heterogêneos mantenham-se juntos sem deixar de ser heterogêneos; [...]" (DELEUZE; GUATTARI, 1997, p. 141). A unidade corporal é diferença e embate.

Então, ao convocarmos Keleman (1992a, p. 15) para este debate, poderíamos dizer que também para o autor o corpo é a própria materialização de um composto de forças, pois é próprio do processo da vida ser conduzida por um "impulso para a organização". Tais forças, para este autor, são sempre ondulantes, pulsantes, peristálticas, elásticas e móveis. Por isso, com Keleman, ao invés de falarmos em termos de qualidades tensivas, diríamos que a singularidade de cada corpo está na sua pulsação própria. "A pulsação é altamente flexível e adaptável às forças" (KELEMAN, 1992a, p. 26), ou seja, a maneira própria de um corpo pulsar tem relação com as forças que o atravessam. A pulsação seria, pois, a expressão imediata das maneiras como as forças tensionam o corpo. Poderíamos dizer que tanto a qualidade da tensão quanto a pulsação são o que dizem da consistência de um corpo. Para Keleman, sendo corpos, estamos organizados em camadas, bolsas, tubos e válvulas, os quais justamente irão dar passagem às qualidades pulsáteis. $\mathrm{O}$ processo de constituição de tais camadas forma um contínuo que dá expressão às forças da vida. E esta natureza pulsátil já existe em nós muito antes que cada um seja um corpo inteiramente individuado, pois na primeira célula embrionária já se encontra esta qualidade pulsátil e rítmica.

No processo de nos tornarmos um corpo, esta primeira e mais elementar pulsação vai se complexificando, até ganhar múltiplos ritmos e pulsações simultâneas e entrelaçadas. "Essa é a nossa metamorfose: de células ritmicamente pulsantes para um organismo multirritmicamente pulsante. Esse organismo pode funcionar com padrões dissonantes e assimétricos" (KELEMAN, 1992a, p. 19), ou seja, a vida do corpo não está efetivamente assentada sobre uma harmonia branda. Embora Keleman diga o tempo todo que nosso padrão pulsátil forma um senso de identidade, é preciso lembrar que a imensa parte de vida do corpo acontece fora de uma constância ou igualdade. A simultaneidade com que os processos acontecem no corpo diz do quanto sua inteireza se traça a partir de uma beleza minuciosamente esquizofrênica.

Para Keleman, por outro lado, até mesmo "a célula tem um senso de interioridade" (KELEMAN, 1992a, p. 24), com o qual ela dialoga com o meio externo; há toda uma inteligência do corpo que norteia nossa vida e esta inteligência nos forma, nos dá um contorno, uma carne, sensações de movimento, de pressão, de crescimento e, especialmente, nos traz emoções. "O metabolismo interno é uma forma de pensamento" (KELEMAN, 1992a, p. 42). Com efeito, encontramos traços de identitarismo, familialismo e individualismo em Keleman. O senso de interioridade atribuído às células seria uma "auto-identidade" destas, derivada da resistência interna feita por cada célula à pressão que vem do meio externo (KELEMAN, 1992a). Com efeito, o autor compreende que a motilidade corporal parte de um senso inicial de identidade, a qual se ligaria, ao longo do desenvolvimento de cada sujeito, ao modo como este foi tratado, em primeira instância, dentro de sua família, como ele revela quando fala dos padrões de agressão à forma corporal (KELEMAN, 1992b). Desta maneira, o que o autor chama de trabalho formativo objetivaria alcançar um modo pessoal de constituição corporal pulsátil: os aspectos imediatamente políticos, históricos, ecológicos, econômicos de um tal processo parecem sempre vir depois ou ser quase ignorados.

Contudo, também é verdade que este autor, o tempo todo, nos faz redescobrir um novo corpo, que não o da identidade, mas o do movimento da vida se materializando em nós. É a partir de Keleman que compreendemos que cada onda pulsátil que nos atravessa constitui em nós um novo corpo, o qual pulsa de uma nova maneira.

Assim, vemos que as pulsações sempre correspondem a ondas emocionais, afetos que passam por nosso corpo, ainda que muito sutis. "O projeto do corpo, em sua forma simples, é construir espaços e estruturas para manter a pulsação, de modo a possibilitar atividades especializadas" (KELEMAN, 1992a, p. 41). Dizemos, pois, que os tecidos do corpo são constituições que, em nosso processo de formação, vão sendo tecidas para dar conta das forças que nos passam. Voltemos, então, a Deleuze e Guattari para circunscrevermos filosoficamente uma concepção de afeto e estudemos também a importância do afeto de alegria para a presente discussão.

\section{Alegria: educação, saúde e clínica pelo aumento da capacidade de agir}

Da obra de Deleuze e Guattari (1997), já é bastante conhecida a afirmação - inspirada em Spinoza - de que um corpo se define pelos afetos de que é capaz. Mas, é preciso lembrar que os afetos são sempre complexos e irredutíveis: envolvem uma miríade de linhas afetivas menores, infinitamente decomponíveis. Deleuze destaca, pois, esta irredutibilidade do afeto às ideias que temos, ou seja, ao trabalho intelectual. O afeto é uma variação em nós, relativa a uma realidade, é uma variação que compreende o aumento ou diminuição da capacidade de agir e da força de existir. Os afetos podem, assim, ser alegres ou tristes, conforme sejam capazes de, respectivamente, aumentar ou diminuir nossa capacidade de agir. Se os afetos são irredutíveis às ideias que temos é justamente porque são ligados às variações de estados corporais, são passagens, não podendo ser identificados a um estado dado ou a outro, nem a uma ideia ou imagem que se faça mentalmente.

Acontece que, no encontro entre corpos, estes são afetados seguidamente, ou seja, têm ideias umas depois das outras, sem que necessariamente sejam compreendidos em sua singularidade ou em sua potência e também sem que uma delas seja capaz de conjugar o complexo de afetos circulantes. Portanto, se tratamos dos corpos a partir de suas relações e encontros, também envolvemos aí a alma como aquilo que deve apreender tão velozmente quanto possível aquilo que se passa nestes encontros, compreender o corpo em que nos transformamos em um encontro. Para Spinoza, tanto existe um pensamento li- 
gado ao corpo, quanto 'um pensamento do próprio corpo’, uma lógica específica do nível dos corpos que se dá a ser conhecida para o pensamento. Esta lógica própria é regida por leis de composição e decomposição. Com efeito, na presença de outro corpo, por leis de composição e decomposição, este corpo pode convir ao outro. Se, num encontro com outro corpo, sinto que ele convém ao meu corpo, estabelece-se com ele uma alegria, há uma potencialização dos corpos, e o composto formado se torna outro corpo, duas vezes mais forte.

Cabe, então, apontar o rigor ligado ao conceito de alegria: alegria é uma potência e, como tal, consiste numa quantidade de realidade e, mais profundamente, no aumento da capacidade de agir. "Podemos dizer que a alegria aumenta nossa potência de agir, e a tristeza a diminui" (DELEUZE, 2002, p. 106, grifo do autor). Com efeito, a alegria é mais uma potência do corpo do que apenas um sentimento psicológico, ela implica na ampliação de uma capacidade do corpo e num aumento de quantidade de realidade pela qual ele é capaz de ser afetado.

Trata-se, então, de tomar o afeto de alegria como material de aprendizagem. Novamente, precisamos ser minuciosos. É que, nos encontros, os corpos nunca sentem um só afeto e mesmo um único afeto é já composto e complicado, ou seja, quando de um encontro, os corpos têm sua sensibilidade e pensamento encrespados e, num primeiro momento, podemos ser afetados de alegria sem que sejamos capazes de compreender esta alegria, sem que ela nos leve a conhecer os outros corpos e os nossos pela sua diferença, sua singularidade. Assim, podemos apenas consumir passivamente a alegria, sem que ela multiplique nossos afetos ou amplie nossa realidade e sem, principalmente, aumentar nossa capacidade de agir. Ora, o que entra em jogo aí é o modo de vida ligado à maneira como se conhece os encontros. Deleuze, aliás, lança a ideia de que os modos de conhecimento são também formas de vida, "porque o conhecer prolonga-se nos tipos de consciência e de afetos que lhe correspondem" (DELEUZE, 2002, p. 64).

Desta forma, quando se vive afetos apenas ao acaso, sem toma-los pela diferença que produzem na capacidade de agir, se diz que as alegrias aí conseguidas são passivas. Mas, se ao contrário, se pode conhecer os encontros pela sua força heterogênica, pela singularidade, aí então se constitui sempre um novo conhecimento, uma nova aprendizagem. Ora, o encadeamento de afetos e encontros produz um modo de vida e, se este encadeamento fica restrito a alegrias passivas, o modo de vida daí decorrente é igualmente passivo e limitado.

Portanto, o modo de vida passivo é também capaz de alegrias, mas estas estagnam a capacidade de agir. Assim, somente a partir do momento em que se dá o salto para se pensar e conhecer os encontros a partir da diferença é que se desencadeia uma outra forma de alegria, aquela capaz de multiplicar ativamente os encontros, organizando-os e selecionando-os. "Além disso, quanto mais coisas a mente conhecer, tanto melhor compreenderá suas forças [...]; quanto melhor compreender suas forças, tanto mais facilmente poderá se distinguir a si mesma [...]" (SPINOZA,
2007, p. 43). O aumento de potência, nos apresenta a força da multiplicidade, diríamos, a força de alegria de um encontro. Ora, desta forma, quanto mais um corpo tem relações potentes com outros corpos, tanto mais maneiras de se afetar ele faz existir em sua própria composição, isto é, mais potente ele se torna, mais sensível ele devém.

O conhecimento aí produzido é um conhecimento intenso, pois não se trata mais apenas de consumir formas prontas de alegria, senão de tornar-se um corpo capaz de produzir e organizar encontros aptos a fornecer aumentos de realidade e de capacidade de ação. Neste sentido, vemos ser a alegria uma espécie de disparate-disparador, que nos impulsiona a um conhecimento duplo: o conhecimento dos encontros que nos potencializam e o conhecimento de nossa própria potência de conhecer. Por isso é que, quando filosoficamente discutimos o corpo, necessariamente estamos colocando em pauta aquilo que ele pode e, principalmente, o quão distante podem estar os corpos de sua potência afetiva, dependendo do modo de vida no qual estão sendo fabricados. A partir do esforço diferenciante desencadeado com a tentativa de compreensão dos afetos faz-se a produção das alegrias ativas, e aí temos, enfim, posse formal de nossas potências de agir, pensar e conhecer.

Questionamo-nos, pois, o quanto não deveria ser esta a verdadeira tarefa de uma educação: proporcionar-nos a posse formal sobre nossa potência de conhecer, oferecendo-nos um conhecimento efetivamente voltado para a vida e para as relações que produzimos. Em lugar de uma educação paralogística, que nos priva do conhecimento ao nos empanturrar de informações, poderíamos ter uma educação afetiva e ética, capaz de nos causar vertigem, porém, infinitamente mais rica e efetivamente potencializadora. Além disso, a partir desta interpretação que Deleuze faz de Spinoza, podemos conceber um processo de aprendizagem que não está mais centrado na racionalidade de um sujeito, mas se basearia na construção lenta e experimental de uma sensibilidade afeita à diferença e à multiplicidade. Então, a aprendizagem seria inseparável da ética, isto é, de um questionamento sobre as potências dos corpos e de sua capacidade de agir e alegrar-se. Ao invés de uma suposta neutralidade da racionalidade, se estaria voltando a potência de conhecer em direção a um posicionamento claro em favor da potencialização dos corpos.

Além disso, dentro destas conceituações, encontramos importantes apontamentos críticos para a saúde. Ora, se por um lado mostramos que o problema da educação passa pela construção de modos de conhecer, por outro, fica também claro que na discussão crítica destes modos estão sempre implicados, ao mesmo tempo, as condições em que se colocam os corpos e suas sensibilidades. Nos modos de conhecer sempre está envolvida uma condição de tristeza ou alegria, de passividade ou atividade e, portanto, de saúde ou adoecimento.

Lembremos que os signos indicativos da força dos encontros são sempre os afetos do corpo. No modo de vida passivo vive-se como num brinquedo de carrinho de bate-bate, determinado por puro caos, numa condição 
que, no limite, se torna clausura. Poder-se-ia dizer, ainda, que se vive tal como uma pedra que rola montanha abaixo: as afecções se colocam em nós, assim como a pedra é tomada pela inelutável lei da gravidade e pelos obstáculos do caminho. Sendo passiva diante destas forças, a pedra só pode ir se decompondo e diminuindo. Note-se que não se trata de um problema moral, mas de um questionamento afetivo e, por isso mesmo, ligado à saúde dos corpos. É o poder de afetar e ser afetado, é a potência de agir mais ou menos, de sentir mais quantidade de realidade ou menos, que estão em jogo.

Ora, o problema da saúde se encontra justamente aí: aprender a selecionar os encontros de maneira a produzir um segundo tipo de alegria, a alegria ativa, é o que é necessário para que os afetos não desemboquem numa vida cativa e povoada de impotências. Então, na incapacidade de conhecer e selecionar os encontros, segundo Spinoza (2007), se passa facilmente a depender de superstições e crenças místicas. Portanto, a saúde se definiria eticamente pelo modo de viver capaz de desenvolver critérios de seleção dos encontros para obter o maior número de alegrias possíveis. Este trabalho de seleção, passa pela capacidade de conhecer a si enquanto grau de potência singular e, ainda, conhecer o mundo, enquanto campo de relações distintas e também singulares.

Então, a partir daqui é possível trazermos mais algumas contribuições de Keleman para esta discussão transversal entre educação e saúde. Será ele que nos permitirá fazer a deriva em direção à clínica, pois sua concepção de corporificação nos parece ser a descrição minuciosa do trabalho de sensibilidade e de pensamento que é a produção de conhecimento dos encontros.

Assim como para a leitura deleuzeana de Spinoza, a questão de Keleman acerca da relação entre vida e corpo parece ser a seguinte: como fazer do viver um exercício de construção e realização de potências, a partir da diferença gestada nos encontros e dos afetos aí gerados sem nos perdermos passivamente neles? Esta é uma pergunta ética e, como tal, também uma pergunta clínica, pois tanto na clínica como na ética, a problemática se coloca em torno dos modos de vida e suas respectivas potências. Por isso, diz Keleman (1992b), que é preciso descobrir como queremos organizar a vida, com sua máxima capacidade.

Tão logo, é preciso dizer que, assim como para Deleuze, para Keleman há uma conexão direta entre o modo como se vive e o modo pelo qual se produzem os corpos. Os estados emocionais são afetos das pulsações corporais, as quais fluem pelo corpo, pelas suas câmaras, camadas de tecido, tubos e líquidos, formando correntes contínuas excitatórias; "a excitação é a base da experiência. É conhecimento, informação" (KELEMAN, 1992b, p. 94). O ponto crucial para este autor é que, no caminho da existência, as forças que se imprimem sobre o corpo e o constituem exigem sempre uma mudança de sua forma. Só que esta desenvoltura da materialidade corporal não acontece se não vem acompanhada de uma respectiva alteração nos modos de sentir, pensar e agir nas experiências. Em termos spinozanos, seria dizer que a mudança corporal precisa ser imanente ao pensamento acerca dos encontros. Então, o trabalho clínico se inicia na produção deste contato entre corpo e pensamento. "O importante é reconhecer como cada um de nós permite que a excitação estimule seu corpo e de que forma: como deixa que a excitação o percorra [...]" (KELEMAN, 1994, p.30).

Desta maneira, Keleman não se preocupa com as motivações que justificariam as posturas afetivas e corporais, mas o modo como estas vivências, tomadas como composição de forças, organizaram e constituíram um corpo, um modo de usar e posicionar os músculos, os tendões e esqueleto, um modo de fazer fluir as emoções, líquidos e oxigênio. Ora, se o corpo não consegue se transformar, é porque também as emoções estão estagnadas numa forma, como Keleman diz, estereotipada. Isso quer dizer, em outras palavras, que Keleman trabalha num campo estético e expressivo, preocupando-se com os processos de geração e gestação de maneiras de produzir os corpos. Esta gestação estética de modos corporais, novamente, implica sempre um aspecto educacional e, mais além, também tem caráter político.

Para aprofundarmos um pouco mais a discussão a esse respeito, recorreremos brevemente a Nietzsche. O filósofo alemão nos traz a educação, em primeiro lugar, como um dos meios pelos quais a humanidade, isto é, a espécie mais do que o indivíduo, acumula grandes quantidades de forças para que as gerações jovens possam continuar o trabalho dos antepassados, de maneira "que não somente externamente, mas internamente, organicamente, elas saem mais fortes [...]" (NIETZSCHE, 2011, p. 347). Assim, este é um primeiro aspecto do conceito nietzschiano de educação que nos é útil para pensarmos as práticas corporais como práticas educacionais: a educação para Nietzsche tem a ver com fortalecimento orgânico e este termo pode muito bem ser entendido como processo corporal. Além desse sentido, há mais um que nos interessa para relacionarmos os corporalismos e a educação. Para Nietzsche, a educação caminha no sentido da formação dos indivíduos. Assim, diz ele, os poucos educadores que de fato formam um indivíduo são aqueles os quais possibilitam ao indivíduo encontrar aquilo que realmente é, "o sentido original e a substância fundamental da tua essência", a qual, estranhamente, diz Nietzsche (2011, p. 165), "não está oculta dentro de ti, mas colocada infinitamente acima de ti, ou pelo menos daquilo que tomas comumente como sendo teu eu". Portanto, a educação deve ser um processo formativo, em que os indivíduos possam tornar-se o que são, mas compreendendo que este "o que são" não está dado, todo feito como quisto perdido em um interior. Pelo contrário, aquilo que é a mais forte potência de cada indivíduo é encontrado através de um processo formativo, é construído, porque está além, na superação de si, no devir de uma força insuspeita e na desconstrução do que se supõe ser "o Eu".

Destaquemos, então, que em Keleman, também encontramos noções que dialogam com esta concepção nietzschiana de formação-educação. Ora, a chamada “jornada formativa” (KELEMAN, 1995, p. 97) não é outra coisa senão um processo contínuo de auto-atualização e realização do próprio potencial, no qual cada um de 
nós está implicado enquanto parte do processo das forças da vida ela mesma. O processo formativo é um processo educacional, em que os indivíduos aprendem modos de organizar seu corpo para desenvolverem suas potências. É nisto que reside alguma aproximação entre as concepções de formação em Nietzsche e Keleman. Enquanto para Nietzsche educar é formar, para Keleman, formar é educar; mas, para ambos, o processo formativo pode estar diretamente ligado ao estabelecimento de uma força, ou seja, à produção de um corpo.

Porém, para Keleman a formação se dá como um contínuo de experiências corporais que se relacionam com um tipo específico de força, as emoções. Por isso é que Keleman (1992a, p. 166) também chama o seu trabalho clínico de "educação somática", entendido como um modo de agir junto às vidas das pessoas, no sentido de auxiliá-las em seu processo de auto-organização e aprendizagem de "critérios que o indivíduo usa para se autoadministrar”. A jornada formativa é um caminho de práticas e aprendizagens de modos de compor e decompor formas de vida emocional, a partir da experiência corporal. Então, por um lado, o processo formativo clínico é necessariamente educacional e, por outro, esta educação se ancora primeiramente na construção de experiências e experimentações corporais. Assim, a formação pode ser entendida como um trabalho clínico, sendo simultaneamente educacional e promotor de saúde.

\section{Corpolítica: capitalismo e questões para um corporalismo ético-estético}

Contudo, é preciso politizarmos e complexificarmos tais concepções, destacando que esta jornada formativa é tecida num campo social, sendo atravessada por poderes e forças de diversas ordens: culturais, midiáticas, históricas, tecnológicas, econômicas, biológicas etc. Reich (2001) mostrava, por exemplo, que existia, no momento de ascensão do nazismo, um caráter narcisista na modulação corporal e afetiva da massa alemã como um todo, o que possibilitava o sentimento nacionalista através da identificação com a ideia de grandeza da nação. Seria em função de terem ignorado as profundas raízes neuróticas da sociedade que as tentativas revolucionárias dos partidos esquerdistas teriam falhado. Acontece que, para Reich, em uma sociedade que se sustenta sobre valores repressores à sexualidade, se constroem Estados necessariamente autoritários, porque os indivíduos, não podendo encontrar satisfação de sua libido, não conseguem também ter uma regulação natural de seus afetos. Esta pequena passagem por Reich nos interessa para mostrarmos que, originalmente, há uma preocupação política muito presente no corporalismo, a qual foi bastante esquecida pelo olhar exclusivamente clínico dos posteriores terapeutas corporalistas, incluindo-se aí Keleman.

Baseando-nos nas concepções políticas de Deleuze e Guattari, entendemos que, em primeiro lugar, o elemento político do trabalho junto ao corpo se encontra em enfrentarmos o modo de produção de vida do capitalismo. Dizem Deleuze e Guattari (1976) que o capitalismo opera necessariamente a partir de uma descodificação e dester- ritorialização generalizada do campo social. As propriedades se desconstroem, os trabalhadores se descolam das propriedades e são tornados livres para vender sua força de trabalho, fluem por toda parte elementos desterritorializados. Mas, a principal desterritorialização é a da moeda, que no capitalismo se torna "equivalente geral" com "valor particular qualquer" (DELEUZE; GUATTARI, 1976, p. 287). A moeda se torna dinheiro e passa a portar um valor abstrato axiomatizante, ou seja, qualquer fluxo ou coisa pode ganhar um valor, porque o valor dos valores dentro do capitalismo é um signo sem conteúdo, uma imensa superfície que engancha tudo sobre seu tecido. $\mathrm{O}$ capitalismo opera uma paradoxal lógica: ele é uma formação de natureza esquizofrênica, não homogênea, que, ao fim, constitui uma única e mesma lógica, um único e mesmo processo de produção e economia (DELEUZE; GUATTARI, 1976). E como o capitalismo se torna capaz de tal paradoxo? Ora, se consideramos que nossa contemporaneidade funciona sob a égide do "capitalismo mundial integrado" (CMI), cuja "existência semiótica insere-se sistematicamente no conjunto dos movimentos locais de desterritorialização técnicos e sociais que ele 'diagramatiza' e reterritorializa nas formas de poder dominantes" (GUATTARI, 1981, p. 198), se vivemos assentados hoje sobre a fragmentação e ruina das referências, acompanhada de uma velocidade cada vez mais vertiginosa de recolocação de formas anacrônicas, fica fácil compreender como, no CMI, estamos modulados por uma lógica que, simultaneamente, nos impele todos a uma exterioridade aniquilante e nos impinge pacotes pré-fabricados de maneiras de viver, sentir e agir. Acerca desta vertigem vivida no CMI, Favre (2010) nos alerta para o perigo constante de nos tornarmos consumidores de fast forms, imagens e formas prontas de estilos de vida e de corporificação, que são oferecidas pelo mercado como socorro à desagregação que somos passíveis de sofrer repentinamente. Daí a importância de adotarmos uma postura crítica quanto a estereotipias no modo de corporificação.

Assim, Keleman, destaca sempre a importância de nos perguntamos sobre "Como?" as experiências se corporificam em nós. A importância de nos perguntarmos "Como?" o corpo se produz nas experiências está no fato de que, a partir das descobertas desta estilística da plasticidade corporal, se pode acessar passo a passo as ordens dentro dos eventos e, dessa maneira, romper com estereotipias (KELEMAN, 1994). A pergunta "Como?" inaugura um processo de auto-afetação e autogestão, abre-se a sensibilidade para estar presente aos próprios processos corporais. Ademais, o estudo do como, envolvendo os afetos corporais, nos dá a exata percepção de que a vida é um processo, um contínuo de intensidades, algo que, com Spinoza chamaríamos de encadeamento. Todo encontro gera o que Keleman chama de imagem somática, isto é, uma composição e forma que o corpo encarna através de seus músculos, órgãos, nervos e vasos, naquela experiência. Segundo o autor, esta imagem corporal tem aspectos externos (sociais) e internos (KELEMAN, 1995), os quais, diríamos em linguagem spinozana, afetam os outros corpos e também geram uma auto-afetação do corpo consigo 
mesmo. O mais importante no trabalho clínico é, pois, que os corpos possam contatar este afeto de si, ou seja, clinicar consiste em refletir como o corpo se afeta a si próprio nos encontros, conhecer a natureza destes afetos e em que constituição corporal estes afetos nos colocam. O encadeamento de diversos modos de composição corporal, ou a produção contínua de corporificações é que perfaz um modo de vida. Segundo o autor, não há respostas para este exercício, há apenas novas maneiras de corporificar nossas experiências. Trata-se de um trabalho ativo que liga os afetos que passam por nós com o corpo que podemos nos tornar - devir - em cada encontro. Nesta ação clínica, se estaria, portanto, também realizando uma intervenção político-estética, na medida em que, ao se desconstruírem estereotipias nos modos de expressão e corporificação, se estaria também desarranjando as formas prontas impostas no capitalismo e abrindo espaço para a singularização dos corpos e respectivos modos de viver.

É preciso destacarmos, pois, que a pergunta "Como?" se refere a modos, maneiras, e subentende o movimento do tornar-se, do devir; "Como?" não tem por resposta a descoberta de essências e substâncias, para as quais a pergunta seria “O que?" e o verbo seria o "ser". Ao questionarmos os modos, através da pergunta "Como?" temos por resposta, então, o desenvolvimento de estéticas e estilos. Portanto, para Keleman, como para a interpretação deleuzeana de Spinoza, conhecer os afetos do corpo é um trabalho do pensamento sobre si próprio, afinal, facilmente percebemos que se trata de um processo afetivo, no qual se mexe com ondas nervosas e com a sensibilidade que se volta para si própria para compreender-se, aprender sobre si. Clínica é, pois, o processo de singularizar os corpos em sua potência de afetar e ser afetado, em sua potência de alegrar-se e agir: processo ético, estético e político, mas também educacional e promotor de saúde.

Ora, se a alegria é mais o aumento da capacidade de agir do que um sentimento psicológico, se ela também implica em mais realidade, então o trabalho clínico é compromisso ético com a produção de modos de vida ativos, tarefa educacional de fabricar conhecimento para que os corpos possam ser expressos em mais quantidade de realidade e exercício de promoção de saúde, esta entendida como construção e seleção de alegrias.

Enfim, um corporalismo que transversalize clínica, saúde e educação não pode se furtar nunca de pensar-se como prática política a qual, na tessitura de estéticas singularizantes, se desafie a desviar-se das estereotipias, especialmente as secretadas pelo modo de produção de vida do capitalismo. Uma tal prática tenderá, pois, a assumir a alegria como afeto norteador e referência ética, porém, compreendendo-a como aumento da capacidade de agir e ampliação dos afetos de que um corpo é capaz.

\section{Referências}

BAIOCCHI, M.; PANNEK, W. Taanteatro: teatro coreográfico de tensões. Rio de Janeiro: Azougue, 2007.

DELEUZE, G. Nietzsche e a Filosofia. Porto: Rés-Editora, 2001.

DELEUZE, G. Espinosa: filosofia prática. São Paulo: Escuta, 2002.

DELEUZE, G.; GUATTARI, F. O Anti-Édipo: capitalismo e esquizofrenia. Rio de Janeiro: Imago, 1976.

DELEUZE, G.; GUATTARI, F. Mil platôs: capitalismo e esquizofrenia. São Paulo: Editora 34, 1997. v. 4.

FAVRE, R. Trabalhando pela biodiversidade subjetiva. Cadernos de Subjetividade, São Paulo, p. 108-123, 2010. Disponível em: <http://www.atelierpaulista.com/wp-content/ uploads/2011/01/Cadernos-de-Subjetividade-2010-Nucleo-deEstudos-da-Subjetividade.pdf>. Acesso em: 13 fev. 2017.

GUATTARI, F. Revolução molecular: pulsações políticas do desejo. São Paulo: Brasiliense, 1981.

KELEMAN, S. Anatomia emocional. São Paulo: Summus, 1992a.

KELEMAN, S. Padrões de distresse. São Paulo: Summus, 1992b.

KELEMAN, S. Realidade somática. São Paulo: Summus, 1994.

KELEMAN, S. Corporificando a experiência: construindo uma vida pessoal. São Paulo: Summus, 1995.

NEGRI, T. Cinco lições sobre Império. Rio de Janeiro: DP\&A, 2003.

NIETZSCHE, F. Escritos sobre Educação. São Paulo: Loyola, 2011.

REICH, W. Psicologia de Massas do Fascismo. São Paulo: Martins Fontes, 2001.

SPINOZA, B. Tratado da Reforma do Entendimento. São Paulo: Escala, 2007.

Recebido em: 16 de março de 2017 Aceito em: 9 de junho de 2017 